\title{
The Influence of Glucose Availability on Events during Germination of Syncephalastrum racemosum Sporangiospores
}

\author{
By J. A. HOBOT AND K. GULL \\ Biological Laboratory, University of Kent, Canterbury, Kent CT2 $7 \mathrm{NJ}$ \\ (Received I4 July I976; revised I0 September 1976)
}

\begin{abstract}
SUMMAR Y
Germination of Syncephalastrum racemosum sporangiospores was studied in shake flask and batch fermenter cultures. In the presence of glucose, spore swelling preceded outgrowth of germ tubes; dry weight increased markedly only at the time of germ tube emergence. Glucose was essential for initiation of these events. Both swelling and germ tube emergence quickly ceased when glucose-grown cultures were shifted down to non-permissive glucose-free medium. Spore swelling was not a prerequisite for germ tube emergence. Analysis of size distributions within populations of partially germinated spores indicated that larger spores germinated first.
\end{abstract}

\section{INTRODUCTION}

Recent research on fungal spores has shown that a complex series of biochemical and ultrastructural events occur during the germination sequence (Van Etten, Bulla \& St Julian, 1974; Weber \& Hess, 1976). Light microscopy of germinating spores usually reveals two gross morphological processes: spore swelling and germ tube emergence. In many fungi these developmental changes are only initiated if the spores are placed in a nutrient medium. The influence of the various components of such media on germination has not been widely characterized. A low molecular weight carbon source such as glucose is, however, essential for complete germination of macroconidia of Fusarium culmorum (Marchant \& White, 1966), conidia of Penicillium notatum and Trichoderma lignorum (Martin \& Nicolas, 1970), and sporangiospores of Rhizopus arrhizus (Ekundayo \& Carlile, 1964).

We have studied the requirement of Syncephalastrum racemosum sporangiospores for an exogenous glucose supply during germination. Studies were made of the requirement for glucose at various periods in the germination sequence and of the effects of temporary glucose deprivation on spore swelling and germ tube emergence.

\section{METHODS}

Organism. The laboratory strain of Syncephalastrum racemosum used throughout this study was kindly donated by Dr Jane North (Department of Biology, City of London Polytechnic).

Growth medium. The fungus was grown on the following defined medium $\left(\mathrm{g} \mathrm{l}^{-1}\right)$ : glucose, Io; $\left(\mathrm{NH}_{4}\right)_{2} \mathrm{SO}_{4}, 6: \mathrm{Na}_{2} \mathrm{HPO}_{4}$. $\mathrm{I}_{2} \mathrm{H}_{2} \mathrm{O}$, I I $5 ; \mathrm{KH}_{2} \mathrm{PO}_{4}, 9 \cdot 3 ;$ EDTA, 0.6; $\mathrm{MgSO}_{4} \cdot 7 \mathrm{H}_{2} \mathrm{O}, 0 \cdot 25$; $\mathrm{CaCl}_{2}, 0.05 ; \mathrm{ZnSO}_{4} .7 \mathrm{H}_{2} \mathrm{O}, 0.02 ; \mathrm{CuSO}_{4} \cdot 5 \mathrm{H}_{2} \mathrm{O}, 0.005 ; \mathrm{FeSO}_{4} .7 \mathrm{H}_{2} \mathrm{O}, 0 . \mathrm{I} ; \mathrm{Na}_{2} \mathrm{SO}_{4}, 0.5$; $\mathrm{Na}_{2} \mathrm{MoO}_{4} \cdot 2 \mathrm{H}_{2} \mathrm{O}, 0 \cdot 005$. Phosphates, ammonium sulphate and the chelated trace elements were autoclaved separately at $\mathrm{I} 2 \mathrm{I}{ }^{\circ} \mathrm{C}$ for $\mathrm{I} 5 \mathrm{~min}$. Glucose was autoclaved at $\mathrm{I}$ I $5{ }^{\circ} \mathrm{C}$ for 
$10 \mathrm{~min}$ : the alternative carbon sources were sterilized in the same manner. Solid medium was produced by adding I $5 \mathrm{~g}$ agar to $\mathrm{I} 1$ medium.

Spore production. The fungus was grown on $100 \mathrm{ml}$ solid defined medium in Roux bottles at $37^{\circ} \mathrm{C}$ for 7 days and then stored at $25^{\circ} \mathrm{C}$ until required.

Germination studies. Spores were approx. 3 weeks old when harvested. They were washed out of two Roux bottles, containing sporulated mycelium, with sterile distilled water and filtered through four layers of sterile muslin to remove hyphal debris. The spore concentration of the filtrate was determined using a Fuchs-Rosenthal haemocytometer. Spores were then centrifuged at $2800 \mathrm{~g}$ for $2 \mathrm{~min}$, washed once with distilled water, centrifuged again and resuspended to a known concentration in sterile distilled water. Germination experiments were done using $25 \mathrm{ml}$ defined medium in $250 \mathrm{ml}$ Erlenmeyer flasks on an orbital shaker at $185 \mathrm{rev} . \mathrm{min}^{-1}$. Unless otherwise stated, the final spore concentration was $\mathrm{I} \cdot 26 \times 10^{6}$ spores per $\mathrm{ml}$ culture medium. Some germination experiments were carried out in a batch fermenter consisting of a I 1 Quickfit pot containing $500 \mathrm{ml}$ medium. The pot was fitted with inoculation and sampling ports, sterile air inlet and outlet ports with air flow control. The aeration rate was $300 \mathrm{ml} \mathrm{min}^{-1}$. The medium was agitated by a propeller shaft connected to an overhead electric motor. Samples $\left(0.4 \mathrm{ml}\right.$ from the flasks: $5^{\circ} \mathrm{ml}$ from the fermenter) were examined microscopically to assess germination. Spores were considered germinated if the length of their germ tube was at least half their diameter; percentage germination counts were calculated from observations of 200 spores. Spore diameters were measured on the screen of a Reichert Visopan microscope (Reichert-Jung, Slough, Buckinghamshire) using a calibrated ruler. Average spore diameters were calculated from measurements of 50 spores. Calculations of size distributions were also made from this group of 50 spores.

All germination experiments were carried out at $37^{\circ} \mathrm{C}$.

Shift experiments. To transfer spores from glucose medium to glucose-free medium, shake flask cultures were filtered through Millipore filters $(0.45 \mu \mathrm{m}$ pore size, $47 \mathrm{~mm}$ diam.), washed twice with $12.5 \mathrm{ml}$ sterile glucose-free medium and resuspended in the appropriate volume of fresh glucose-free medium. For transfers from glucose-free medium to glucose medium, spores were filtered, washed twice with $12.5 \mathrm{ml}$ sterile glucose medium and resuspended in the appropriate volume of fresh glucose medium. The final resuspension medium and washing medium were prewarmed to $37^{\circ} \mathrm{C}$ and the whole procedure was carried out as swiftly as possible in an incubation room maintained at $37^{\circ} \mathrm{C}$.

Germination events. Freshly harvested spores of $S$. racemosum had a yellow refractile appearance when viewed by phase contrast microscopy. This refractility was lost and phase darkening occurred upon swelling of the spores. After germ tube formation, spores started to clump forming aggregates which gradually became visible to the naked eye. This aggregation made counting of germ tubes more difficult at later stages. It was found that brief sonication in a Millipore ultrasonic cleaning bath disaggregated spore clumps without breaking the cells. At about $\mathrm{I} 2 \mathrm{~h}$, clumping of spores with long germ tubes became so extensive that counting was no longer feasible. In this study we use the term 'germination' to describe all the events from initiation to outgrowth of the germ tube.

\section{RESULTS}

The carbon source of the defined medium was varied to determine the range of compounds that would support outgrowth of the germ tube. Succinate and citrate did so very poorly, whilst sucrose and fructose gave higher rates of outgrowth (16\% and $46 \%$ of 


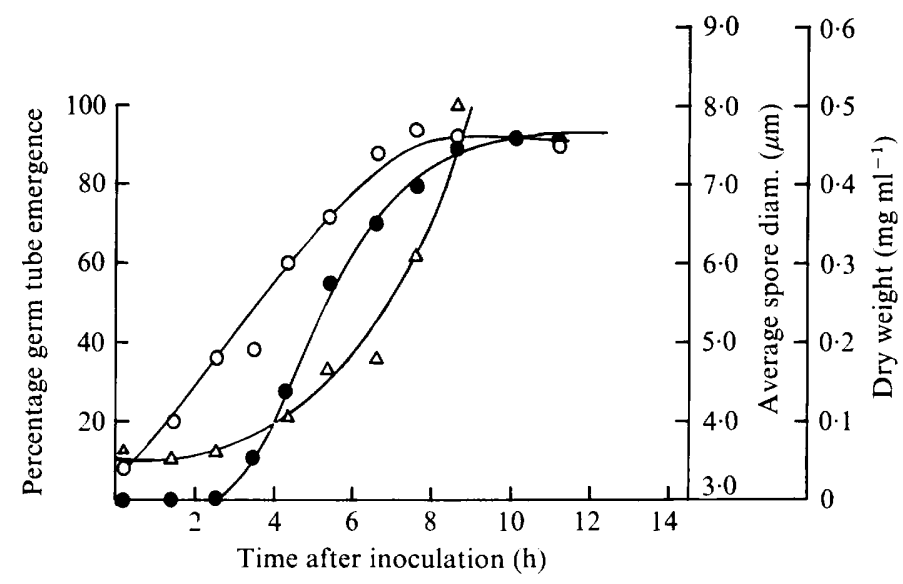

Fig. I. Germination of spores in a typical batch fermenter culture. emergence; $O$, average spore diameter; $\triangle$, dry weight. The concentration of spores was $1 \cdot 5 \times 10^{6}$ per ml culture medium.

spores had germ tubes at I I $h$, respectively). The highest rates were obtained with galactose and glucose. Glucose was chosen as the carbon source for all subsequent experiments.

Spore swelling, the percentage of the spore population with germ tubes and dry weight data for germination in a batch fermenter culture are presented in Fig. I. Spores began to swell soon after inoculation into the defined medium and the increase in spore diameter was linear for the first $6.5 \mathrm{~h}$ of germination, the overall increase in size being from 3.4 to $7.6 \mu \mathrm{m}$. Outgrowth of germ tubes was first noticed at $3.5 \mathrm{~h}$ and reached a maximum $(92 \%)$ by $10 \mathrm{~h}$. Dry weight of the spores increased noticeably just after the emergence of the first germ tubes. The range of spore diameters within this population (Fig. 2) indicates that all the spores within the culture increase their size during germination. There is no overlap in the size distribution of the spore population at $\mathrm{O} h$ and at $\mathrm{II} \cdot 25 \mathrm{~h}$.

If glucose was omitted from the medium, outgrowth of germ tubes did not occur. Spores deprived of the carbon source also did not swell or undergo phase darkening indicating that glucose was required even in these early pre-outgrowth stages of germination. Varying the final glucose concentration of the defined medium affected the rate of germ tube outgrowth and consequently the percentage of the population with germ tubes at $12 \mathrm{~h}$. Increasing the glucose concentration to about $\mathrm{I} \%(\mathrm{w} / \mathrm{v})$ also caused an increase in the number of spores with germ tubes in the population. Further increase in the glucose concentration above I $\%(w / v)$ had little effect on the level of germ tube outgrowth.

\section{Shift-down to non-permissive conditions}

Knowing that glucose was essential to ensure normal development of germinating spores, we studied the effects of shifting a culture from glucose medium to glucose-free medium at various points in the germination sequence. Spores were transferred to glucose-free medium at hourly intervals after inoculation into glucose medium. Average spore diameters and germ tube production were monitored before and after the shift. A compilation of the results of these experiments is given in Fig. 3 where the average spore diameter of the population at $\mathrm{I} 2 \mathrm{~h}$ is plotted against the time spent in the glucose medium. It can be seen that the longer the period spent in the glucose medium before shift-down, the larger the final average spore diameter. This curve parallels the data for the increase in spore diameter in 


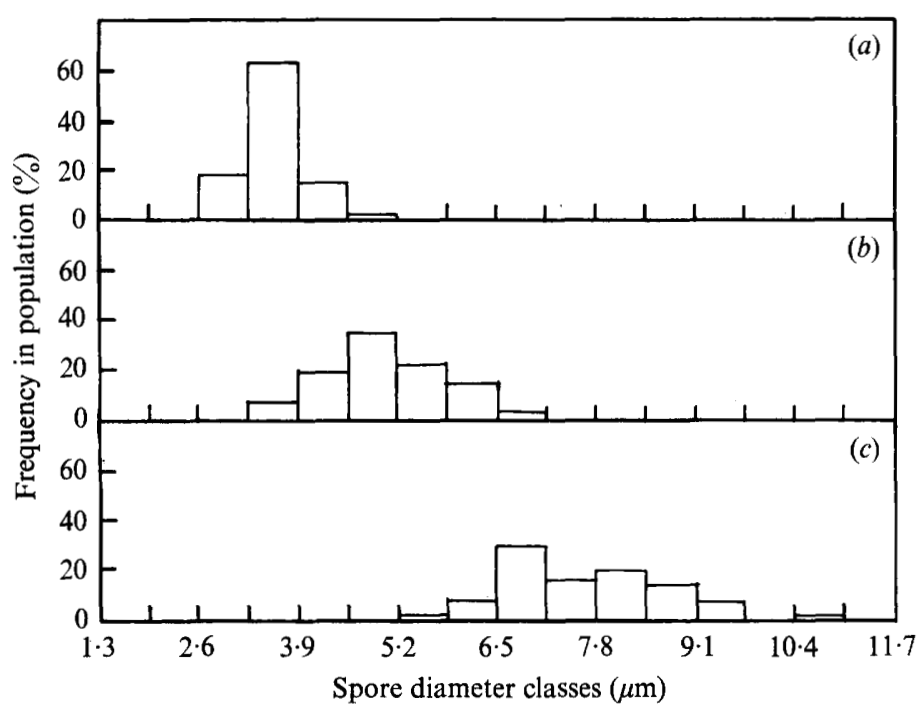

Fig. 2. Histogram of frequency of different sized spores in the population. (a) $\circ \mathrm{h}$ after inoculation; average spore diameter $3.4 \mu \mathrm{m}$; percentage germ tube emergence 0 . (b) $2.5 \mathrm{~h}$ after inoculation; average spore diameter $4.8 \mu \mathrm{m}$; percentage germ tube emergence $0.5 \%$. (c) I I. $25 \mathrm{~h}$ after inoculation; average spore diameter $7.5 \mu \mathrm{m}$; percentage germ tube emergence $92.0 \%$.

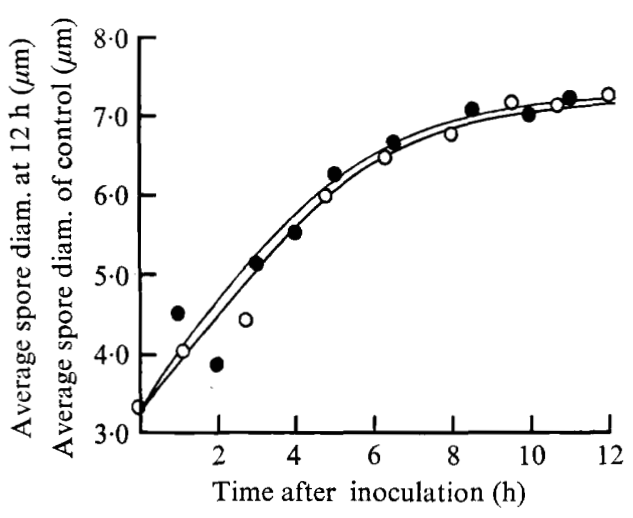

Time in glucose medium before transfer $(\mathrm{h})$

Fig. 3

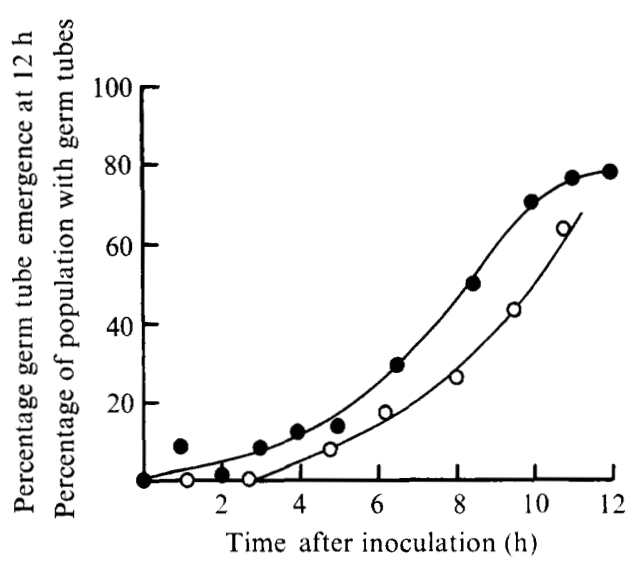

Time in glucose medium before transfer $(\mathrm{h})$

Fig. 4

Fig. 3. Compilation of the results from shift-down experiments. Spores were shifted down to glucose-free medium at hourly intervals and the average spore diameter was assessed at $\mathrm{I} 2 \mathrm{~h}, \boldsymbol{O}$. $\bigcirc$, Control curve for a culture that was not shifted down.

Fig. 4. Compilation of results from shift-down experiments for germ tube emergence. Spores were shifted down to glucose-free medium at hourly intervals and the percentage germ tube emergence was assessed at $\mathrm{I} 2 \mathrm{~h}, \mathrm{C}$. Control curve for a culture that was not shifted down.

a normal control culture (Fig. 3). Similar results were obtained (Fig. 4) for the percentage of the population with germ tubes at $\mathbf{I 2} \mathrm{h}$. The longer the period spent in glucose medium, the higher the number of spores with germ tubes in the population at $\mathrm{I} 2 \mathrm{~h}$. Spore populations which had been shifted down after I, 2 or $3 \mathrm{~h}$, times at which germ tube outgrowth 


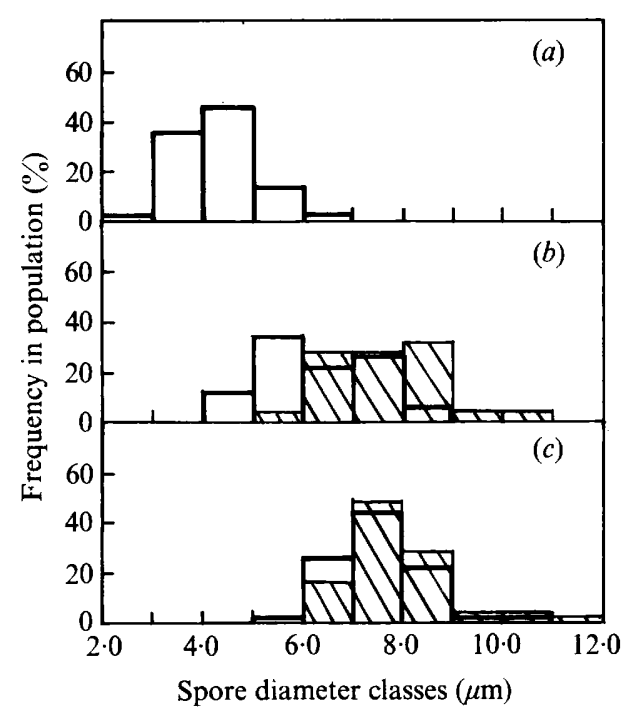

Fig. 5

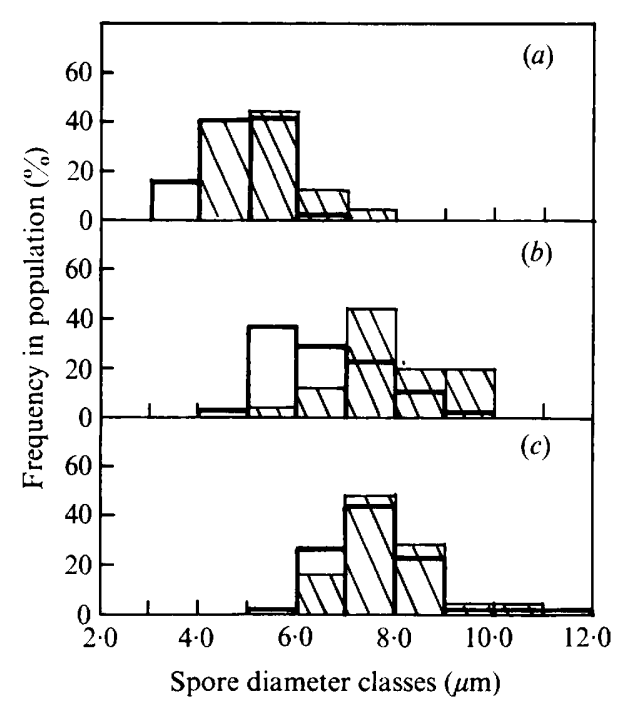

Fig. 6

Fig. 5. Histograms of the frequency of spore diameter classes in the total population (unshaded areas, outlined in thick lines) and amongst those spores with germ tubes (shaded areas). (a) $\mathrm{I} \cdot 2 \mathrm{~h}$ after inoculation; average spore diameter $4.0 \mu \mathrm{m}$; percentage germ tube emergence 0 . (b) $4.75 \mathrm{~h}$ after inoculation; average spore diameter $6.0 \mu \mathrm{m}$; percentage germ tube emergence $7.5 \%$; average diameter of spores with germ tubes $7.4 \mu \mathrm{m}$. (c) $\mathrm{I} 2.00 \mathrm{~h}$ after inoculation; average spore diameter $7 \cdot 3 \mu \mathrm{m}$; percentage germ tube emergence $78 \%$; average diameter of spores with germ tubes $7.5 \mu \mathrm{m}$.

Fig. 6. Histograms of the frequency of spore diameter classes in the total population (unshaded areas, outlined in thick lines) and amongst those spores with germ tubes (shaded areas). In this experiment spores were sized at $\mathrm{I} 2 \mathrm{~h}$ but had spent varying times in glucose before a shift-down to a glucose-free medium. ( $a$ ) Time spent in glucose medium $\mathrm{I} h$; percentage germ tube emergence at $\mathrm{I} 2 \mathrm{~h} 8.5 \%$; average spore diameter at $\mathrm{I} 2 \mathrm{~h} 4.5 \mu \mathrm{m}$; average diameter of spores with germ tubes $5.1 \mu \mathrm{m}$. (b) Time spent in glucose medium $5 \mathrm{~h}$; percentage germ tube emergence at $12 \mathrm{~h} 13.5 \%$; average spore diameter at $\mathrm{I} 2 \mathrm{~h} 6.3 \mu \mathrm{m}$; average diameter of spores with germ tubes $7 \cdot 7 \mu \mathrm{m}$. (c) Time spent in glucose medium $12 \mathrm{~h}$; percentage germ tube emergence at $12 \mathrm{~h} 78 \%$; average spore.diameter at $12 \mathrm{~h} 7 \cdot 3 \mu \mathrm{m}$; average diameter of spores with germ tubes $7 \cdot 5 \mu \mathrm{m}$.

had not started in the control cultures, did produce some germ tubes (Fig. 4) even though glucose had been removed and swelling had ceased prematurely.

Figure 5 shows the range of spore diameters within a population of germinating spores at different times. As germ tube formation begins it is the larger members of the spore population which produce the first germ tubes (Fig $5 b$ ). The histogram for the spores with germ tubes in Fig. $5 b(4.75 \mathrm{~h}$ after inoculation) occupies the larger diameter classes of the histogram of the total spore population. Eventually, as spore swelling and germ tube outgrowth increase and reach their maximum values, these two size distributions merge (Fig $5 c$ ).

Size distributions were assessed at $\mathrm{I} 2 \mathrm{~h}$ for spore populations which had been in glucose medium and then shifted down at various times to glucose-free medium These analyses showed that a population contained more spores in the larger diameter classes the longer the initial period spent in glucose medium (Fig. 6). Again, the spores with germ tubes were the larger spores of the population (Fig. $6 a, b$ ). Spores which had been in glucose medium for only $\mathrm{I} \mathrm{h}$ before shift-down still managed to produce some germ tubes $(8 \cdot 5 \%$ at $\mathrm{I} 2 \mathrm{~h})$. Figure $6 a$ shows that in this extreme population it was the larger spores which tended to produce the germ tubes. 


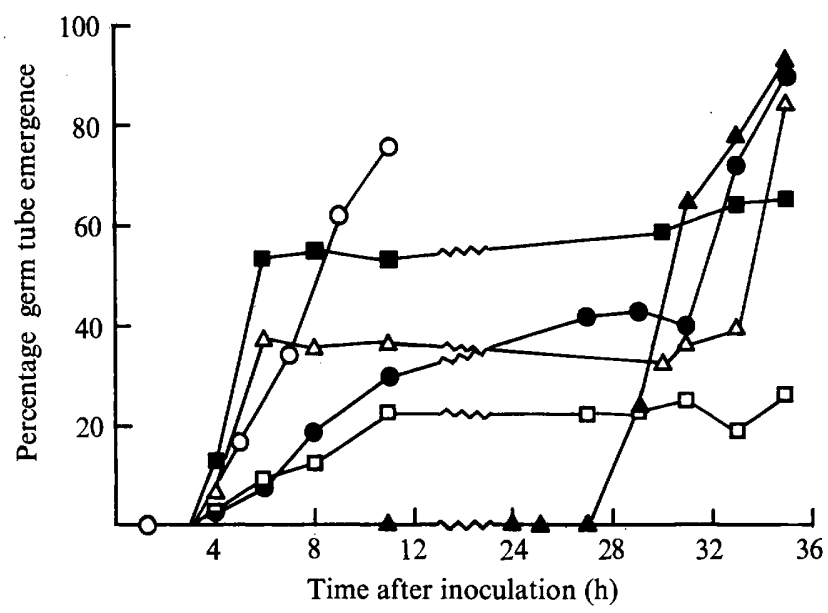

Fig. 7. Spores were shifted down to a glucose-free medium at 3 or $6 \mathrm{~h}$ and shifted back to glucose medium $24 \mathrm{~h}$ later. $O$, Control spores in glucose medium; $\boldsymbol{\Delta}$, spores in glucose-free medium shifted up to glucose medium at $24 \mathrm{~h} ; \mathbf{n}$, spores shifted down to glucose-free medium at $6 \mathrm{~h} ; \Delta$, spores shifted down to glucose-free medium at $6 \mathrm{~h}$ and shifted back at $30 \mathrm{~h} ; \square$, spores shifted down to glucose-free medium at $3 \mathrm{~h}$; 0 , spores shifted down to glucose-free medium at $3 \mathrm{~h}$ and shifted back at $27 \mathrm{~h}$.

\section{Shift-down/shift-up}

We observed the effect on spores of a shift-down to non-permissive germination conditions followed, some time later, by a shift-up back to glucose medium. Spores were inoculated into glucose medium and then shifted down to glucose-free medium after 3 or $6 \mathrm{~h}$; $24 \mathrm{~h}$ after the shift-down cultures were transferred back to glucose medium. The number of spores producing germ tubes was monitored throughout the experiment and the results are presented in Fig. 7. Removal of glucose at 3 or $6 \mathrm{~h}$ stopped germ tube development. The shift-up to glucose medium $24 \mathrm{~h}$ later resulted in an increase in germ tube outgrowth after a lag period. This lag was about $4 \mathrm{~h}$ for the culture which had been shifted down at $3 \mathrm{~h}$ and about $3 \mathrm{~h}$ for the culture shifted down at $6 \mathrm{~h}$. Spores which had been incubated in glucose-free medium for $24 \mathrm{~h}$ and were then shifted up to glucose medium showed a lag of about 3.5 to $4 \mathrm{~h}$ before a near normal sequence of germ tube outgrowth started in the population. Microscopic examination of the cultures undergoing the shift-down/shiftup protocol suggested that spores which had already formed germ tubes before glucose deprivation did not develop further when glucose was again available after the shift-up.

\section{DISCUSSION}

Spore germination in Syncephalastrum racemosum follows a developmental sequence of spherical spore swelling, localized outgrowth of the germ tube and subsequent polarized growth of the new hypha. Spore swelling precedes the emergence of germ tubes whilst the dry weight appears to increase markedly only at the time of germ tube emergence. This pattern of germination and dry weight increase is similar to that observed by Van Etten et al. (1974) in sporangiospores of Rhizopus stolonifer.

Our results show that glucose is essential for both spore swelling and germ tube emergence. If glucose is absent from the incubation medium neither of these morphological processes is initiated. Incubation in glucose-free medium does not appear to affect viability 
and spores will germinate almost normally if glucose is added subsequently. The fact that the normal lag period of 3 to $4 \mathrm{~h}$ is present before such spores produce germ tubes implies that glucose is required at the very start of the germination sequence. Also, varying the concentration of glucose in the incubation medium produced variations in the rates of germ tube emergence.

The shift-down experiments from glucose medium to glucose-free medium in the first few hours of incubation show that swelling was particularly glucose dependent. Glucose is essential throughout the first io $h$ for the spores to achieve the normal size before germ tube formation. The shape of the normal germination curve and the shift experiments show that there is variation in the time taken for an individual spore within the population to produce a germ tube. Brief exposure to glucose during the first few hours of incubation followed by removal of the glucose resulted in some germ tube outgrowth at $\mathrm{I} 2 \mathrm{~h}$. It is, however, the larger members of these populations which produce the germ tubes even though they are smaller than the normal size at germ tube emergence. It is known that cell wall growth, RNA, DNA and protein synthesis continue, or are initiated, during this swelling phase (Weber \& Hess, 1976; Gull \& Trinci, 1971; Schmit \& Brody, 1976; Van Etten et al., 1974). Our results with $S$. racemosum, however, indicate that complete spore swelling is not a prerequisite for outgrowth of the germ tube. Similar results have been obtained with another phycomycete, Rhizopus arrhizus (Ekundayo \& Carlile, I964).

Analysis of size distributions of partially germinated spore populations, scoring sizes of all spores and sizes of only those with germ tubes, indicates that the fully germinated spores occupy the larger size classes in the histograms. Such a variability within the population is analogous to that found for Schizosaccharomyces pombe (Padilla, Carter \& Mitchison, 1975). Spores of this fission yeast were separated into distinct size classes and it was found that the size depended on the duration of the pre-germination interval. Large spores germinated up to $6 \mathrm{~h}$ before the smaller ones. In future studies where synchrony of germ tube emergence is a priority it may be useful to separate size classes of fungal spores before inoculation into nutrient medium.

We thank the Science Research Council for financial support for J.A.H.

\section{REFERENCES}

Exundayo, J. A. \& CARLILE, M. J. (1964). The germination of sporangiospores of Rhizopus arrhizus: spore swelling and germ tube emergence. Journal of General Microbiology 35, 261-269.

Gull, K. \& TRINCI, A. P. J. (I97I). Fine structure of spore germination in Botrytis cinerea. Journal of General Microbiology 68, 207-220.

MARChANT, R. \& White, M. F. (1966). Spore swelling and germination in Fusarium culmorum. Journal of General Microbiology 42, 237-244.

Martin, J. F. \& Nicolas, G. (1970). Physiology of spore germination in Penicillium notatum and Trichoderma lignorum. Transactions of the British Mycological Society 55, I4I-148.

Padilla, G. M., Carter, B. L. A. \& Mitchison, J. M. (1975). Germination of Schizosaccharomyces pombe spores separated by zonal centrifugation. Experimental Cell Research 93, 325-330.

Schmit, J. C. \& Brody, S. (1976). Biochemical genetics of Neurospora crassa germination. Bacteriological Reviews 40, I-4I.

Van Etren, J. L., Bulla, L. A. \& St Julian, G. (1974). Physiological and morphological correlation of Rhizopus stolonifer spore germination. Journal of Bacteriology II7, 882-887.

Weber, D. J. \& Hess, W. M. (1976). The Fungal Spore, Form and Function. London: John Wiley. 